\title{
LA DINAMICA SALARIAL DURANTE \\ EL FRANQUISMO. \\ EL CASO DE RENFE
}

ANTHONY FERNER * y LLUIS FINA * *

\section{INTRODUCCION}

El análisis de una cuestión tan importante como es la evolución del poder adquisitivo de los trabajadores durante el período franquista tropieza con graves dificultades debido a la inexistencia de series estadisticas continuas y suficientemente fiables acerca de los niveles salariales prevalecientes en dichos años. El Instituto Nacional de Estadística (INE) no inició hasta 1963 la elaboración de una Encuesta de Salarios dirigida a establecimientos seleccionados por muestreo aleatorio. Aunque la nueva encuesta tenía una cobertura limi. tada y adolecía de diversos problemas metodológicos (Serrano y Malo de Molina, 1979: 331-346; Lorente, 1982), supuso una mejora muy importante respecto a la situación anterior en que la única información oficial disponible se limitó a unos datos de ganancias obtenidos por el INE desde 1953, que constituyen el precedente inmediato de la Encuesta de Salarios mencionada, y unos datos de "tarifas salariales» publicados por el mismo Instituto. Los datos de ganancias se obtenían a partir de «una muestra de empresas, en número aproximado de 500 , seleccionadas con criterios opináticos, entre las más importantes de cada provincia» (INE, 1982: 5), por lo que plantean serios problemas de representatividad; solamente se ha publicado, además, la infor-

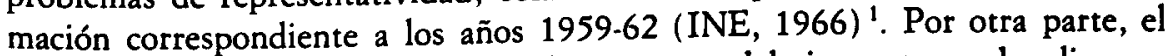
INE publicó, durante las décadas del cuarenta y del cincuenta, en las diversas ediciones de su Anuario Estadístico de España, unas series de salarios nominales extraídad, al parecer, de las tarifas salariales establecidas en las Reglamentaciones de Trabajo vigentes ${ }^{2}$. Esta información, que por ser la única disponible ha

* Industrial Relations Research Unit, Warwick University.

** Departament d'Economía Aplicada, Universitat Autònoma de Barcelona.

Según Velarde (1973: XXVI), la información correspondiente al período 1953-58 se perdió para siempre. En ICE (1962), refiriéndose, al parecer, a la misma encuesta, se indica que la muestra era de 3.000 empresas, que la información era recogida desde 1956 y que los resultados no se publicaron «por la falta de confianza en la consistencia de los datos* (ICE, 1962: 77).

2 Así se indica, por lo menos, en la información publicada relativa a los años 1952 
sido utilizada para analizar la evolución del poder adquisitivo de los salarios durante la inmediata postguerra (Fontana y Nadal, 1976: 510-511; Cañas, 1976: 19), plantea el grave problema de la medida en que la evolución de las tarifas salariales refleja la de las ganancias efectivamente obtenidas por los trabajadores, ya que, especialmente durante el franquismo, la diferencia entre los dos conceptos salariales mencionados no sólo fue importante, sino que fue cambiando a lo largo del tiempo (Perpiñá, 1962: 51-68; Serrano y Malo de Molina, 1979: 85-228).

Estas carencias de la información estadística procedente de fuentes oficiales pueden ser suplidas, aunque sea parcialmente, mediante el recurso a otras fuentes, como los diversos organismos privados o semipúblicos, que pueden haber realizado alguna labor de recogida de datos (por ejemplo, algunas Cámaras de Comercio e Industria o algunas asociaciones empresariales), o bien acudiendo a los archivos de empresas individuales. Existe aquí un campo de investigación muy amplio, apenas explorado. Como trabajos pioneros, tanto más importantes cuanto que cubren los períodos en que las carencias de las fuentes oficiales son mayores, debe citarse la serie de salarios reales en la industria de Sabadell elaborada por la Cámara de Comercio e Industria de dicha localidad y recogida por J. Maluquer (1987: 972) para los años 1939. 1959 y, sobre todo, los «estudios de casos» realizados por C. Molinero y P. Ysàs (1985: cap. 4) en diversas empresas del área industrial de Barcelona para la década del $40^{3}$.

Con el presente trabajo se pretende ofrecer una nueva aportación en esta misma línea de investigación, analizando la dinámica de los salarios en una sola empresa, la Red Nacional de Ferrocarriles Españoles (RENFE), la más importante del país por el volumen de su plantilla. Se distingue de los trabajos citados en que se han recogido datos para un período más prolongado, que cubre prácticamente todo el franquismo, desde 1943, año en que se completa el proceso de integración en RENFE de las antiguas compañías ferroviarias

y siguientes. Estos datos presentan algunos rasgos anómalos como, por ejemplo, la invariabilidad de los niveles salariales entre 1947 y 1953, a pesar de que en estos años se revisaron numerosas Reglamentaciones. A partir de 1954, la serie publicada hasta entonces es sustituida por un nuevo conjunto de datos en que se hace referencia explícita a la Reglamentación y categoría profesional de que se trata en cada caso y en que se eapecifica, aunque sin definirlo, que el concepto salarial considerado es el de usalario-base íntegro». Esta «nueva serie», no obstante, sólo refleja entre el año citado y 1962, la última fecha a que se refieren los datos, los cambios de niveles salariales que, como se señala más adelante, se producen en 1956.

${ }^{3} R$. Carballo (1976: 187) había presentado, con anterioridad, una información relativa a la evolución de los salarios medios de Telefónica durante el período 1940-1953. Aunque dicho autor es poco claro al respecto, parece que estos datos se refieren más a tarifas salariales que a ganancias medias percibidas por los trabajadores y, por ello, adolecen de los mismos problemas que se acaban de mencionar respecto a los datos del Anwario. 
nacionalizadas en 1941 para la constitución de la nueva empresa pública, hasta 1975, año de la muerte del dictador. Como es bien sabido, con este hecho se inicia la transición hacia el restablecimiento de un sistema de democracia y libertad sindical, que comporta cambios importantes en la gestión de las relaciones laborales y en los procesos de determinación de los salarios de las empresas españolas, incluyendo, lógicamente, a RENFE (Ferner, 1987).

Una segunda característica que distingue este trabajo reside en el hecho de que presenta información no sólo sobre la evolución de las ganancias medias de los trabajadores, sino también sobre la de diversos componentes del salario; concretamente, se analiza la evolución de la parte fija del salario y. la de algunos elementos variables relacionados - al menos, teóricamentecon la intensidad del trabajo, tales como "primas» de diversas denominaciones, o con la duración del trabajo, como la remuneración correspondiente a jornada extraordinaria. Esta parte del análisis puede servir para ilustrar, en el caso de esta empresa, la cuestión cuya importancia ha sido subrayada antes: la magnitud de la diferencia, y la evolución de la misma, entre los salarios base (el concepto salarial más cercano a las tarifas mínimas determinadas en las Reglamentaciones) y las ganancias efectivamente percibidas por los trabajadores.

Como toda información procedente de «estudios de casos», tanto la de los trabajos citados como la que se presenta en este artículo, debe ser tratada con sumo cuidado a la hora de extraer conclusiones que se quieran aplicar a un ámbito más amplio que aquel en el que ha sido generado. Esto es particularmente cierto en el caso de una empresa como RENFE, que presenta ciertas peculiaridades que es preciso resaltar. Se trata, ante todo, de una empresa pública que, por ello, está sometida a restricciones financieras muy distintas de las que limitan la actuación de las empresas privadas en mercados competitivos. Además, dentro del sector público empresarial, se trata de una empresa que se ha caracterizado por mantener unos rasgos organizativos peculiares. La importancia estratégica que concedió el Ejército al sistema ferroviario, tanto desde el punto de vista de la defensa nacional como del control de la población interior, hizo que mantuviera siempre una presencia muy activa en RENFE, desde el reclutamiento y formación del personal hasta el mantenimiento de una estructura empresarial de carácter paramilitar. Ello significó que las posibilidades de organización y de presión colectiva por parte de los trabajadores fueran siempre menores que las prevalecientes en otras grandes empresas. A la amenaza de «militarización» se añadía la actuación de la temida «brigadilla», grupo especial de la Guardia Civil creado para la persecución de los delitos contra la propiedad dentro de la empresa, pero que prestaba una atención especial a todo conato de actividad sindical por parte de los trabajadores (Martino de Jugo, 1980: 162). Por otro lado, a diferencia 
de lo ocurrido en otras grandes empresas públicas, la dirección de RENFE no aceptó nunca durante todo el período franquista la posibilidad de determinar los salarios y otras condiciones laborales mediante la negociación colectiva.

A pesar de todas estas peculiaridades, creemos que el interés del análisis de la dinámica salarial de una empresa como RENFE supera ampliamente los límites de la misma, tanto desde un punto de vista histórico como desde un punto de vista puramente teórico. Desde una perspectiva histórica, no debe excluirse, por lo menos a nivel de hipótesis, la posibilidad de que existan im. portantes paralelismos entre la dinámica salarial de RENFE y la del conjunto de la economía. Por esta razón, la evidencia empírica relativa a RENFE se irá comparando con los datos disponibles, muy fragmentarios, como se ha dicho, sobre el conjunto de la economía. Con ello, esperamos que este trabajo contribuya positivamente a la tarea de ir delimitando el perfil temporal y las principales características de la dinámica de los salarios durante el franquismo, a sabiendas de que para alcanzar una «síntesis definitiva» todavía se requerirá la aportación de muchas otras investigaciones parciales como la presente.

En segundo lugar, desde una perspectiva teórica, las mismas peculiaridades de RENFE abren la interesante posibilidad de investigar el grado de "permeabilidad" de su dinámica salarial respecto a la del conjunto económico en el que se encuentra inserta, y convierten este caso en un banco de pruebas privilegiado de la hipótesis repetidamente planteada por la denominada «escuela institucionalista» (Dunlop, 1957; Piore, 1973) de que uno de los principales factores determinantes de la evolución de los salarios de una empresa concreta, o de un determinado submercado de trabajo, reside en la preservación de los salarios relativos establecidos por la costumbre. De ser así, las diferencias salariales interempresariales tenderán a presentar una cierta rigidez, la cual no tiene por qué ser absoluta, sino que puede ir cambiando a lo largo del tiempo, dependiendo, entre otros factores, de la fuerza y de las características precisas de los «mecanismos de transmisión», los cuales dependerán, a su vez, de las características específicas del «marco institucional» de determinación de los salarios vigente en cada momento. En este aspecto, el caso español es particularmente interesante dada la importancia de las transformaciones que ha experimentado dicho marco institucional durante un período de tiempo relativamente breve 4 .

4 En este trabajo daremos por conocidos los rasgos principales de este «marco". Baste señalar la línea divisoria fundamental que comporta la puesta en vigor de un sistema de negociación colectiva en 1958 que, aunque sometido a fuertes controles, daba cierta autonomía a las partes implicadas en la fijación de los salarios, en contraste con la situación anterior en que los salarios dependían del Ministerio de Trabajo o, a lo más, de las decisiones unilaterales de los empresarios. Para un análisis más detallado de estos cambios, véanse Fina $(1978,1979)$ y Serrano y Malo de Molina (1979). 
Además de esta introducción, la exposición se ha estructurado en tres apartados. En el apartado 2, que sigue a continuación, se analiza la evolución de los salarios medios por trabajador en RENFE, tanto en términos monetarios como en términos reales, y se compara esta evolución con la que refleja la información disponible para el conjunto de la economía. En el apartado 3 se estudia la composición de los salarios en RENFE, según diversos conceptos salariales, y la evolución experimentada por la misma a lo largo del período considerado. Finalmente, en el apartado 4 se resumen las principales conclusiones del análisis. Los datos relativos a RENFE que se presentan en este trabajo han sido extraídos de las diversas ediciones de la Memoria Anual de la empresa; la información básica, así como las definiciones de los principales conceptos salariales utilizados, se presentan en un Apéndice Estadístico.

\section{LA EVOLUCION DE LAS GANANCIAS MEDIAS EN RENFE, 1943-1975}

En este apartado se analiza la evolución de las ganancias medias por trabajador en RENFE calculadas simplemente por cociente entre la Masa Salarial total de la empresa y el número de trabajadores ${ }^{5}$. Tal como puede observarse en el gráfico 1, en que se presentan las tasas de variación de los salarios,

'Este procedimiento, aunque no plantea serios problemas para obtener el perfil de la evolución de los salarios a medio plazo, puede hacer que para años determinados se obtengan incrementos salariales que sean poco representativos de la evolución real de los salarios medios. Ello podría deberse a que las variaciones de plantilla estuvieran muy concentradas en determinadas categorías de trabajadores, con niveles salariales muy distintos de los medios; a cambios producidos por otras causas en la estructura ocupacional de la plantilla o a que determinadas variaciones de salarios estuvieran muy concentradas en un grupo muy concreto de trabajadores. Existe evidencia empírica de que alguno de estos factores pudo ser importante en algún momento. Asi, buena parte de los trabajos realizados por los trabajadores «eventuales» fueron subcontratados a otras empresas a medida que se redujo este componente de la plantilla (véase Apéndice Estadístico). En algunos momentos se procedió a ureclasificaciones» importantes de la plantilla, como ocurrió en 1964, en que se promocionó a un gran número de trabajadores a la categoría de «obrero especializado», lo cual comportó un aumento de la Masa Salarial del orden de 330 millones de pesetas (Memoria, 1966: 68), aunque, en este caso, pudo tratarse simplemente de una forma encubierta de conceder aumentos salariales. Igualmente, a lo largo de los años sesenta se produjo una reducción rápida de un grupo con salarios muy bajos, como el «personal subalternow, que entre 1963 a 1969 pasó de 15.000 a menos de 8.000 , o del 12 por 100 al 9 por 100 de la plantilla. Por último, otro factor que puede sesgar ligeramente al alza los incrementos salariales es el derivado del aumento de la edad media de la plantilla que pudo darse en los momentos de descensos más intensos de la misma - en el caso de que éstos se produjeran mayoritariamente por un freno de las nuevas contrataciones o una aceleración de las jubilaciones- y de la importancia que, en los salarios, tenían las remuneraciones por antigüedad. 


\section{GRAFICO 1}

Evolución de los salarios medios de RENFE, nominales y reales, 1944-1975 (Porcentajes de variación anual)

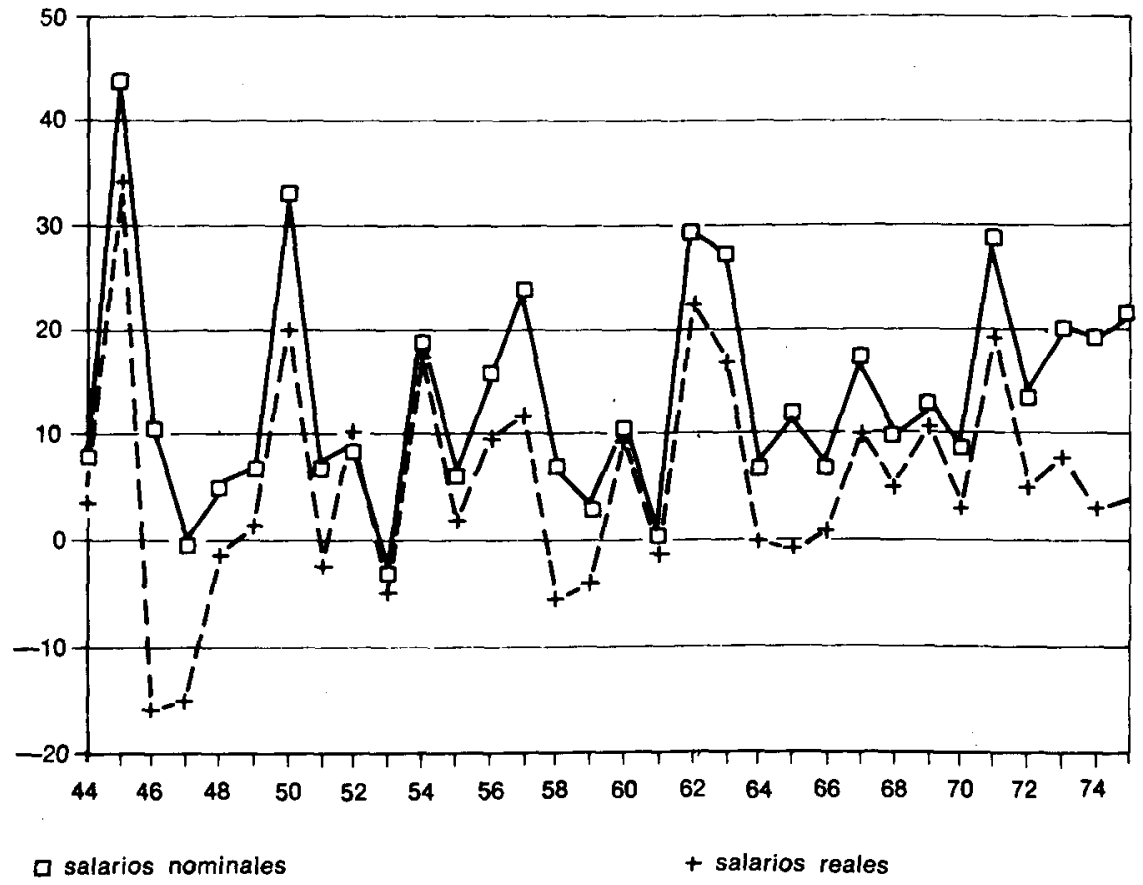

Furnte: Cuadro A.2 del Apéndice Estadístico.

tanto en términos monetarios como en términos reales ${ }^{6}$, se pueden distinguir dos fases bien diferenciadas. Desde 1943 hasta 1966, se observan grandes fluctuaciones de los salarios reales, con aumentos importantes que siguen a caídas también importantes $\longrightarrow$, por lo menos, a estancamientos prolonga-

- El índice utilizado como deflactor ha sido el que se deriva de las «series enlazadas» del índice de precios de consumo elaboradas por el INE (1979: 159-160). Para el período $1943-61$ se han tomado los datos relativos al "conjunto nacional urbano», por ser los únicos disponibles, y para el período restante, los datos relativos al «conjunto nacional total» (cuadro A.2 del Apéndice Estadístico). Debe advertirse que es prácticamente seguro que estos índices infravaloran los procesos inflacionistas de la economía española, especialmente los de los años cuarenta, en que muchos productos básicos estaban racionados y existía un amplio mercado negro en el que estas subsistencias sólo podían obtenerse a precios muy por encima de los oficiales. 
dos- de esta variable. Por el contrario, a partir de 1966, los salarios reales en RENFE crecen de una manera continuada año tras año. Dada esta diferencia radical de comportamiento, dividiremos la exposición en dos partes. No obstante, la línea divisoria la situamos en 1960, por considerar que se trata de una fecha más relevante, ya que marca el fin del período de ajuste que comporta el Plan de Estabilización de julio de 1959 y que, a partir de la misma, empieza a generalizarse la negociación colectiva como mecanismo de determinación de los salarios en las grandes empresas; en el caso de RENFE, además, 1960 marca el inicio del período en que no se observan ya las grandes reducciones de salarios reales de los años anteriores.

\section{3-1960}

Los aumentos de salarios reales más importantes que se observan en este período son los de los años 1945, 1950, 1952, 1954, 1956-1957 y el del año que lo cierra, 1960. El primero de estos incrementos, el de 1945, está claramente ligado a la entrada en vigor de la primera Reglamentación de RENFE (BOE: 14-1-45) y se produce en un año de profunda crisis económica, de origen principalmente agrario, y de incertidumbre política ligada al fin de la II Gran Guerra. El intenso proceso inflacionista que siguió a esta crisis del cuarenta y cinco, no obstante, erosionó rápidamente las ganancias obtenidas; tres años más tarde, en 1948, el poder adquisitivo de las ganancias de los trabajadores de RENFE se encontraba por debajo del nivel alcanzado en 1943. A pesar de que la Reglamentación no fue revisada, los salarios monetarios experimentaron cierto crecimiento que sirvió para aminorar, al menos parcialmente, estas pérdidas. El mecanismo institucional utilizado para ello fue la concesión de primas especiales; así, por ejemplo, el ligero incremento del salario real que se observa en 1949 es atribuible a la introducción de unas nuevas primas en concepto de «movilidad» y de «regularidad» (Memoria, 1949: 7-8). Los incrementos de 1950, 1954 y 1956 corresponden a modificaciones de la Reglamentación ( $B O E$ : 5-4-50, 17-4-54, 27-11-56), que coinciden con revisiones de un amplio número de Reglamentaciones. Por su parte, el aumento de 1952 corresponde a la «paga extraordinaria» concedida, también con carácter casi general, a finales de aquel año (BOE: 1-11.52; Clavera et al., 1978: 304-305). Adviértase, no obstante, que con la primera de estas revisiones, que comportó un incremento de los salarios monetarios del orden del 33 por 100 , no se llegó ni siquiera a alcanzar el nivel de salarios reales establecido en la Reglamentación de 1945. Sólo con la revisión de 1954, en el contexto de una excepcional estabilidad de precios, se superó en un 3,2 por 100 el poder adquisitivo del salario del cuarenta y cinco. 
En 1956, tras unos fuertes conflictos sociales, se producen unos intensos crecimientos de salarios decretados por el ministro José Antonio Girón, conocidos como «el gironazo». Dadas las fechas de entrada en vigor de las disposiciones correspondientes, sus efectos se distribuyeron entre 1956 y 1957. Obsérvese en este caso que, a diferencia de lo ocurrido en 1954, tras los incrementos salariales se desataron intensas presiones inflacionistas que erosionaron rápidamente las ganancias reales obtenidas. En 1960 el salario real se encontraba todavía ligeramente por debajo del nivel alcanzado en 1957, a pesar de que se trata de otro año en que se produjo un fuerte aumento de los salarios reales producido, principalmente, por la introducción de una «prima de incentivo de productividad y reducción de efectivos» ${ }^{7}$ (Memoria, 1960: 13-62).

En síntesis, desde la primera Reglamentación de RENFE hasta la línea divisoria de 1960, las ganancias medias reales de los trabajadores de RENFE crecieron en un 28,2 por 100 , lo cual equivale a una tasa de variación anual media del 1,7 por 100 . El crecimiento más intenso se dio en la segunda mitad de los cincuenta, con una tasa de variación anual media del 3,7 por 100 entre 1954 y 1960, frente a una del 0,4 por 100 entre 1945 y 1954. Los salarios monetarios, en cambio, experimentaron una evolución muy distinta. Entre 1945 y 1960 crecieron a una tasa anual media del 9,9 por 100 , pero en los dos subperíodos divididos por 1954 las tasas de variación fueron muy parecidas: el 9,1 por 100 en el primero y el 11 por 100 en el segundo.

¿En qué medida estos cambios fueron paralelos a los de los salarios medios de la economía? Aunque, como se ha dicho, la información disponible es muy escasa, parece claro que durante la década de los cuarenta se produjo un estancamiento o, quizá, una ligera reducción de los salarios reales, en una situación de estancamiento económico caracterizada por fuertes fluctuaciones de precios, muy concentradas en el tiempo, producidas fundamentalmente por crisis agrarias, seguidas de fluctuaciones también muy fuertes y de forma «saltuaria», en expresión de M. de Torres (1956), de las tarifas salariales. Algunos de los casos estudiados por Molinero e Ysàs (1985) muestran esta rigidez de los salarios nominales a corto plazo y la estabilidad o ligera reducción de los salarios reales en el conjunto de la década; por ejemplo, frente a una variación anual media de los precios del 11,5 por 100, las ganancias nominales de los trabajadores aumentaron el 9,3 por 100 en el caso de Bracons y Riera,

' Este incremento de 1960 no aparece en los datos de «remuneraciones medias efectivas por hora de trabajo» relativos a RENFE recogidos por el INE (1966). Esta anomalía podría reflejar la práctica de esconder unos incrementos salariales -que, sin duda, infringian abiertamente las directrices del Plan de Estabilización de julio de 1959que se concedian por haberse llegado, posiblemente, a una situación de malestar dentro de la empresa por la degradación del poder de compra de los salarios o por no obtener incrementos salariales semejantes a los de otras empresas. 
el 10,2 por 100 en el caso de Tranvías de Barcelona y el 9,3 por 100 en el caso de la remuneración diaria de los oficiales de primera de Ferrocarriles de Cataluña. A corto plazo, estos casos también muestran la pauta de largos períodos de estabilidad de los salarios monetarios, tanto en empresas públicas como en empresas privadas, y de fuertes elevaciones de los mismos tras caídas repentinas de su poder de compra; muestran, asimismo, que estas modificaciones «saltuarias» de los salarios nominales no se produjeron simultáneamente, sino en diferentes momentos del tiempo.

Es interesante subrayar el papel que representaron los «pluses» especiales para atemperar en alguna medida las caídas de salarios reales producidas por la rigidez del sistema de Reglamentaciones. Durante estos años proliferan, como únicos elementos que dotan de una cierta flexibilidad al sistema, los "pluses» de carestía de la vida o pluses de carácter más permanente, como el «plus familiar». No obstante, las correcciones introducidas por estos pluses normalmente eran insuficientes, y sólo la revisión periódica de los salarios básicos de las propias Reglamentaciones permitió ir recuperando los niveles adquisitivos erosionados por la inflación.

En contraste con el estancamiento de los años cuarenta, en los años cin. cuenta se produjeron mejoras significativas del poder adquisitivo de los salarios, en un contexto de crecimiento. Así, los datos de ganancias reales de Paris Eguilaz, presentados por Clavera et al. (1978: 223), muestran un crecimiento anual medio entre 1950 y 1957 de los salarios industriales del orden del 5,2 por 100 y de los salarios agrícolas del orden del 7,3 por 100 . El caso de RENFE se sitúa en un nivel intermedio, con un crecimiento anual del 6,1 por 100 entre los años citados.

Este crecimiento de los salarios reales se obtuvo en una situación de mayor estabilidad de precios, que crecieron a una tasa anual media del 5,2 por 100, frente al 11,5 por 100 citado de la década anterior. No obstante, la estabilidad de precios fue mucho mayor en la primera mitad de la década que en la segunda; así, los incrementos medios de precios fueron el 2,8 por 100 en el primer quinquenio y el 7,6 por 100 en el segundo. Además, este mayor crecimiento de los salarios reales se obtuvo también mediante revisiones más frecuentes de los salarios reglamentados. Estas revisiones, por otro lado, tendieron a ser de carácter general y simultáneo, hecho que se explica porque las más importantes están claramente relacionadas con las presiones ejercidas por los trabajadores a través de amplios conflictos sociales. Así, pues, en esta época el «mecanismo de transmisión» que hace que los logros salariales se generalicen al conjunto de la economía es el protagonismo que asume la Administración en el proceso de determinación de los salarios, unido a una mayor conflictividad que, por dicho protagonismo, adquiere un carácter abiertamente político. 
El repaso de la principal evidencia disponible sobre la evolución de los salarios del conjunto de la economía durante este período permite responder afirmativamente a la pregunta de si se dio cierto paralelismo entre la evolución de éstos y los de RENFE. El paralelismo, sin embargo, no debe llevarse demasiado lejos. Como se ha indicado, la pauta temporal de la evolución de los salarios parece que difirió significativamente de una empresa a otra, en especial durante los años cuarenta, a pesar de que la pauta temporal del principal factor explicativo de dicha evolución, las fuertes fluctuaciones de los precios de las subsistencias, fuera la misma para todos. En los años cincuenta, hay indicios que apuntan que los incrementos se dieron con una mayor simultaneidad, aunque su magnitud pudiera diferir significativamente de una empresa a otra. En el caso de RENFE, parece que los salarios reales tendieron a crecer por debajo del conjunto de la economía en los primeros años de la década; así, mientras, según los datos antes mencionados de Paris Eguilaz, los salarios reales de la industria y la agricultura crecieron, entre 1950 y 1953 , en un 18 y un 20 por 100 , respectivamente, en los mismos años, los salarios reales de RENFE sólo crecieron un 2,8 por 100 . Sin embargo, a medida que la década fue avanzando, los salarios de RENFE crecieron por encima de los del conjunto de la economía, evolución que puede interpretarse como una recuperación tardía del terreno perdido.

Una cuestión final de carácter general que merece algún comentario es la relativa al grado de adecuación de los datos de tarifas salariales para analizar la evolución de los salarios reales de este período. La evidencia considerada muestra cierto estancamiento de los salarios reales a lo largo de los cuarenta, que contrasta con la caída de dicha variable que reflejan las series elaboradas a partir de tarifas. Tampoco coinciden los perfiles temporales que presentan los datos considerados antes y los derivados de las tarifas; mientras los primeros muestran bruscas oscilaciones, tanto al alza como a la baja, los segundos muestran una caída continuada durante la primera mitad de la década de los cuarenta y un cambio de tendencia durante la segunda mitad que supone una cierta recuperación, aunque sólo parcial, de las pérdidas anteriores. En los años cincuenta, por el contrario, es muy posible que los datos de tarifas tiendan a sobrevalorar el crecimiento de las ganancias efectivas debido a que los súbitos incrementos de las tarifas, en muchas ocasiones, fueron «absorbidos» por incrementos salariales concedidos con anterioridad.

\section{0-1975}

A partir de los años sesenta se inicia una nueva dinámica salarial con la progresiva generalización de la negociación colectiva, mecanismo de determi- 
nación salarial que empieza a adquirir cierto peso a partir de 1962, tras el paréntesis marcado por el Plan de Estabilización, en un clima económico de clara expansión. Al parecer, se produjeron crecimientos importantes de los salarios monetarios que, según la escasa evidencia disponible, fueron especialmente pronunciados en los sectores básicos y en las empresas de mayor dimensión, que eran las que tenían más posibilidades de negociar colectivamente sus salarios (Alcaide, 1965: 50).

En RENFE, tras un ligero descenso de los salarios reales, en 1962 se observa un fuerte incremento de esta variable ligado a la revisión de la Reglamentación (BOE: 30-6-62). Dicha revisión, realizada a mediados de año, comportó un aumento salarial del 29 por 100 en 1962 y del 27 por 100 en 1963 , lo cual supone un aumento global de casi el 64 por 100 . Considerando los datos de remuneraciones efectivas por hora de trabajo retogidas por el INE (1966), en 1962 también se observan incrementos importantes que van desde unos valores situados en torno al 80 por 100 , en el caso del «personal de talleres», hasta valores situados en torno al 100 por 100 para el «personal de estación». En parte al menos, estos importantes aumentos salariales suponían situar los salarios de RENFE en niveles similares a los de ocupaciones comparables de otras empresas. Así, según los mismos datos del INE, el aumento del sesenta y dos supuso que los salarios medios de las diversas categorías profesionales de RENFE pasaran de encontrarse un 20-30 por 100 por debajo de los de las categorías análogas de otras empresas de eferrocarriles de uso público» a encontrarse entre un 10 y un 40 por 100 por encima. A conclusiones semejantes se llega si se comparan los salarios de RENFE con los de otros grupos similares de trabajadores como, por ejemplo, el personal empleado en los medios de transporte urbano.

A partir de 1962, sin embargo, los salarios reales medios de RENFE permanecieron prácticamente estancados. Este hecho, por una parte, contrasta con lo ocurrido en el conjunto de la economía en que se observaron importantes incrementos salariales (cuadro 1) y, por otra parte, refleja una diferencia significativa respecto a lo ocurrido en episodios anteriores: no se produce un descenso de los salarios reales, sino que los salarios monetarios se adaptan casi exactamente a la evolución de los precios, preservándose el poder adquisitivo. Este hecho está, sin duda, ligado a la evolución de las «primas» y otras partes variables del salario, que se considera en el apartado siguiente, y, de nuevo, refleja que estos componentes del salario eran utilizados también como instrumentos para mantener el poder de compra de los salarios y, con ello, la paz social dentro de la empresa.

En 1966 se inicia el período de incrementos ininterrumpidos de salarios reales. Este hecho está ligado a un cambio en la política salarial seguida por 


\section{CUADRO 1}

Evolución del Salario Minimo Interprofesional, del salario medio por trabajador en la industria y del salario medio de RENFE, 1964-1975

(Porcentajes de variación anual)

\begin{tabular}{|c|c|c|c|}
\hline$A \tilde{n} o s$ & $S M I$ & Industria & RENFE \\
\hline $\begin{array}{llllll}1964 & \ldots & \ldots & \ldots & \ldots & \ldots \\
1965 & \ldots & \ldots & \ldots & \ldots & \ldots \\
1966 & \ldots & \ldots & \ldots & \ldots & \ldots \\
1967 & \ldots & \ldots & \ldots & \ldots & \ldots \\
1968 & \ldots & \ldots & \ldots & \ldots & \ldots \\
1969 & \ldots & \ldots & \ldots & \ldots & \ldots \\
1970 & \ldots & \ldots & \ldots & \ldots & \ldots \\
1971 & \ldots & \ldots & \ldots & \ldots & \ldots \\
1972 & \ldots & \ldots & \ldots & \ldots & \ldots \\
1973 & \ldots & \ldots & \ldots & \ldots & \ldots \\
1974 & \ldots & \ldots & \ldots & \ldots & \ldots \\
1975 & \ldots & \ldots & \ldots & \ldots & \ldots\end{array}$ & $\begin{array}{r}0,0 \\
0,0 \\
10,0 \\
31,8 \\
0,0 \\
17,2 \\
13,2 \\
14,3 \\
14,4 \\
18,2 \\
20,6 \\
23,7\end{array}$ & $\begin{array}{r}13,0 \\
16,8 \\
16,7 \\
13,6 \\
8,0 \\
11,4 \\
13,6 \\
13,1 \\
15,9 \\
17,5 \\
24,7 \\
28,5\end{array}$ & $\begin{array}{r}6,8 \\
12,3 \\
7,0 \\
17,3 \\
10,0 \\
13,0 \\
8,9 \\
28,8 \\
13,7 \\
20,2 \\
19,3 \\
21,5\end{array}$ \\
\hline
\end{tabular}

FUENTES: - SMI: valores anuales medios calculados a partir de la serie publicada en Ministerio de Trabajo y Seguridad Social, Anuario de Estadisticas Laborales, 1985, Madrid, 1986 (cuadro A.9: 569).

- Industria: salario nominal medio por trabajador en la industria. Medias anuales calculadas a partir de datos de la Encuesta de Salarios del INE, según la agregación publicada en Banco de España, Boletín Estadistico, Series Históricas, X-Empleo y Salarios, Madrid, 1977 (cuadro X-19: 76).

- RENFE: salario nominal medio por trabajador. Cuadro A.2 del Apéndice Estadístico.

el Ministerio de Trabajo, que revisa anualmente los salarios de RENFE desde 1967 hasta 1975, con las únicas excepciones de 1968, que fue un año de congelación salarial para toda la economía, y 1970, el año inmediatamente anterior a la promulgación de la nueva Reglamentación (BOE: 6-2-71). Estas revisiones de los salarios de RENFE se realizaron poco antes de las revisiones del Salario Mínimo Interprofesional, y tienen una cuantía análoga ${ }^{8}$. Esta coin-

- Además de las que se citan en el texto, las fechas de revisión de la Reglamentación de RENFE, año de vigencia y el salario más bajo establecido en la misma, así como las fechas de entrada en vigor y el nivel del Salario Mínimo Interprofesional, fueron:

Reglamentación RENFE

BOE: 6-2-71. Año 1971: 130 ptas.

$B O E:$ 6-2.71. Año 1972: 150 ptas.

BOE: 9.3-73. Año 1973: 180 ptas.

BOE: 7-2-74. Año 1974. 210 ptas.

BOE: 6-2.75. Año 1975: 248 ptas.
Salario Minimo Interprofesional

Entrada en vigor: 1.4-71: 136 ptas.

1-4.72: 156 ptas.

1-4-73: 186 ptas.

1-4-74: 225 ptas.

1.4.75: 280 ptas. 
cidencia entre el crecimiento de los salarios medios de RENFE y el SMI puede observarse claramente en el cuadro 1, para los años 1968-1969 y de 1972 en adelante. No obstante, existen también dos excepciones notables: la primera de ellas en 1966-1967 y la segunda en el año de la revisión de la Reglamentación, 1971, así como en el inmediatamente anterior, en que, como se ha dicho, no se tocaron los salarios de RENFE.

El caso de 1966-1967 merece una atención especial, ya que en estos años se produjo el que, al parecer, fue el primer conflicto colectivo importante de RENFE, que podría explicar el cambio de política salarial que acabamos de mencionar. Tal como describe Bulnes (1967: 85-87; véase, también, Martino de Jugo, 1980: 31-105), ya en la primavera y en el verano de 1966 se había manifestado cierto malestar entre los trabajadores de RENFE ante la pérdida de posición de sus salarios respecto al conjunto de la industria; los datos del cuadro 1 muestran que mientras que, entre 1963 y 1966, los salarios monetatarios del conjunto de la industria crecieron un 54 por 100, en RENFE sólo habían crecido un 28,4 por 100 . En junio de 1966 los trabajadores ferroviarios solicitaron un aumento del 16 por 100 sobre el salario base de 60 pesetas vigente desde 1963, a lo que el Consejo de Administración respondió que «no había ingresos suficientes para hacer efectivo el mayor gasto producido por este aumento». El Jurado de Empresa, a su vez, contestó con la siguiente amenaza de huelga:

Todo lo que haya que hacer se hará, y si por las vías de la normal convivencia y el diálogo, que están a punto de agotarse, no se llegan a alcanzar nuestras justas reivindicaciones, quedará descartada toda la negociación y habrá que pensar en dar paso a la inacción en nuestras actividades laborales, siquiera sea como protesta al comprobar que son tan poco apreciadas y reconocidas. Si esta unidad a que llamamos a todos los ferroviarios no se nos niega, nuestro empuje tendrá más eficacia y nuestros justos propósitos se alcanzarán más rápidamente. ¡Dios nos ilumine a todos! (Madrid, 14 de julio de 1966).

Al mismo tiempo, numerosos trabajadores enviaron a la Dirección una carta impresa, en la que se subraya el agravio comparativo respecto a otros sectores económicos y la incapacidad de las estructuras sindicales vigentes para dar una solución al problema favorable a los trabajadores:

... los ingresos que en estos momentos percibimos los reclamantes han sido vergonzosamente y amplísimamente desbordados por los que perciben, también actualmente y por todos los conceptos, 
muchos sectores de la industria privada. (...) Cuando en nuestra patria actualmente carecemos los obreros de cauces de defensa adecuados, por la subordinación del Sindicato a la política económica del Estado, puede calificarse de cobardía el mantenimiento de unos hombres indefensos en las condiciones de indigencia e injusticia contra las que reaccionamos.

A esta situación se añadió la aprobación del nuevo SMI, situado en 84 pesetas diarias, que entró en vigor el 1 de octubre. La Dirección de RENFE se negó a aplicarlo y, en una circular del 20 de diciembre, estableció para el año siguiente una subida salarial del 16,6 por 100 , la solicitada inicialmente, y un salario-base de 70 pesetas. A partir de este momento se celebran diversas asambleas (de enlaces sindicales de Madrid, a finales de diciembre; de enlaces sindicales de Barcelona, el 17 de enero, etc.) en las que se produce una escalada de reivindicaciones y se ataca cada vez más frontalmente la situación política y sindical vigente. En algunos talleres, donde es más fácil la organización, se producen algunos paros intermitentes.

A pesar de todo, la Dirección se niega a aumentar el salario-base hasta las 84 pesetas argumentando que los salarios más bajos de RENFE superaban este nivel si se tenían en cuenta diversos «devengos absorbibles» (BOE: 8-21963), tales como las "primas de producción». Por ello, el Ministerio de Trabajo, el responsable último de los salarios de la empresa, señalaba que el nuevo SMI

... no ha tenido repercusión en RENFE, en lo referente a las retribuciones directas en jornada normal, ya que en dicha fecha sobrepasaban el importe correspondiente a la aplicación del nuevo salario mínimo, y únicamente afectó a ciertas remuneraciones indirectas, como las horas extraordinarias, dietas y haberes pasivos (BOE: 22-2-67).

No obstante, concedió lo solicitado por los trabajadores, especificando que lo realizaba «recogiendo las aspiraciones expuestas por los agentes a través del cauce sindical» (ibid.), manifestación que constituye una muestra clara de los efectos de la competencia establecida entre el sindicalismo oficial y la oposición sindical en la clandestinidad. Parte del aumento concedido fue compensado, no obstante, con una reducción de la «prima fija» o de «asistencia» (Memoria, 1967: 100-101), que explica la caída de las primas que se observa en 1967 y que se considerará en el apartado siguiente.

Las presiones de los trabajadores parece que incidieron también en la actitud adoptada por la Dirección de la empresa tras la congelación salarial decre- 
tada para 1968, que fue derogada antes de lo previsto en el mes de agosto de este mismo año. De manera casi inmediata, la empresa proclamó que, aunque la «descongelación» no era de forzosa aplicación en el caso de RENFE, «moralmente había llegado el momento de atender las demandas de los representantes del personal», por lo cual la empresa había buscado «una fórmula que permitiera hacer llegar a los agentes las cantidades ofrecidas en su día por la Red» (Circular 358, 15-10-68). La solución encontrada consistía en una gratificación especial de 5.170 pesetas por trabajador, la mitad de la cual se abonaría de una sola vez en octubre de 1968.

Otro punto que debe considerarse en este período es el de la incidencia que tuvieron en RENFE las medidas de control salarial establecidas con carácter general. A pesar de que tales medidas no eran directamente aplicables a esta empresa, por el hecho de que sus salarios no se determinaban a través de la negociación colectiva, es de esperar que sirvieran de guía a la hora de determinar las sucesivas revisiones salariales y la política salarial propia de la empresa.

A este respecto, los datos del cuadro 1 muestran algunas similitudes, pero también algunas diferencias importantes entre lo ocurrido en RENFE y en el conjunto de la economía. La «descongelación» de salarios de 1968 hace que el incremento de salarios monetarios de cerca del 10 por 100 que se observa en dicho año sea compatible con el cumplimiento estricto de la "congelación" previa. En todos los demás episodios, sin embargo, la evolución de los salarios muestra que se desbordaron ampliamente los objetivos señalados por las autoridades económicas. Así, en 1969, el incremento salarial observado fue del 13 por 100 frente al «tope» del 5,9 por 100. En 1970, el incremento observado $(8,9$ por 100$)$ se acerca más al recomendado por el Gobierno del 6,5 o del 8 por 100, según la duración de los Convenios; no obstante, parece que ello se debe más a que la Reglamentación se encontraba en fase de revisión que a un seguimiento más estricto de la normativa general, tal como evidencia el fuerte incremento de salarios monetarios del año siguiente (el 28,8 por $100)$, que desborda claramente las directrices en vigor.

Los otros dos años en que se impusieron controles fueron 1974 y 1975. La norma recomendada fue el incremento del coste de la vida del año anterior, que, en términos anuales medios, alcanzó el 11,5 y el 15,7 por 100, respectivamente, al que excepcionalmente podían añadirse algunos puntos, 5 en 1974 y 3 en 1975. De hecho, la excepción se convirtió en el objetivo mínimo a alcanzar. En RENFE ocurrió algo semejante, con unos incrementos salariales medios que en cada uno de estos dos años se sitúan exactamente 2,8 puntos por encima de la norma excepcional tomada como objetivo. No obstante, este crecimiento de los salarios de RENFE fue sensiblemente inferior 
al experimentado por los del conjunto de la industria, hecho que, de ser real ${ }^{9}$, parece que debería atribuirse al mayor control gubernamental sobre esta empresa.

Resumiendo, la experiencia de los años sesenta y de la primera mitad de los setenta fue de un crecimiento importante de los salarios reales en RENFE. A lo largo de todo el período, esta variable aumentó en un 167,2 por 100 , que equivale a una tasa anual media del 6,8 por 100 , en claro contraste con la experiencia de los quince años inmediatamente precedentes considerada antes. Además, aunque en el conjunto del período los salarios de RENFE crecieron algo por debajo de los salarios de la industria (mientras que, entre 1963 y 1975, estos últimos se multiplicaron por 7,5, los de RENFE sólo se multiplicaron por 5,2), con el paso de los años las diferencias se fueron reduciendo y el comportamiento de los salarios de RENFE fue cada vez más semejante al del conjunto de la economía.

Es importante subrayar el papel crucial que representó el «marco institucional» del proceso de determinación de salarios, así como el de diversos factores de orden sociopolítico. Entre estos últimos, destaca la incidencia del sindicalismo clandestino (Comisiones Obreras y la Unión Sindical Obrera, concretamente), ejercida a través de la competencia que se estableció entre éste y el Jurado de Empresa para ganar legitimidad entre los ferroviarios en la creación de los mecanismos que permitieron que las conquistas que otros grupos de trabajadores alcanzaban en el resto de la economía se «filtraran» de hecho en RENFE, a pesar de la fuerte represión ya mencionada que se practicaba en la empresa contra el sindicalismo clandestino y de la no admisión de negociar colectivamente los salarios y otras condiciones de trabajo. El caso de RENFE también ejemplifica la eficacia que, en su momento, tuvieron las tácticas *entristas» en las estructuras de base del sindicalismo oficial. Así, parece que en las elecciones para el Jurado de Empresa de 1966 las candidaturas «independientes y democráticas» consiguieron importantes victorias, aunque no llegaran a dominar plenamente este organismo (Martino de Jugo, 1980). Por ello, la competencia para ganar legitimidad a que se ha aludido se daba no sólo entre grupos clandestinos y Jurado, sino también, dentro de este último, entre los grupos minoritarios -impulsados por el sindicalismo clandestino- y el grupo mayoritario; es decir, la acción ilegal se combinaba y reforzaba con la acción legal, con el resultado de que el Jurado, en su con-

- Respecto a este episodio, debe señalarse que existen algunas dudas acerca de la calidad de los datos de la Encuestá de Salarios, que para estos años podría sobrevalorar los incrementos salariales y, por ello, también la diferencia de comportamiento entre los salarios de RENFE y los del conjunto industrial. Adviértase, por otra parte, que los datos presentados en la nota anterior muestran también un crecimiento menor del salario-bese más bajo de RENFE respecto al del SMI. 
junto, se vio obligado a apoyar hasta cierto punto las demandas de los trabajadores, especialmente aquellas respecto a las cuales tenían una especial sensibilidad: la preservación de los salarios relativos.

Así, pues, el nuevo sistema de determinación de los salarios establecido en 1958 tuvo, a través de las organizaciones de clase de los trabajadores, una incidencia efectiva en RENFE. Esta incidencia, sin embargo, parece que fue ciertamente menor de la que hubiera tenido la aplicación del sistema de negociación colectiva al caso de RENFE, tal como evidencia la misma resistencia a ello por parte de la empresa y la opinión generalizada entre los ferroviarios de que sus niveles salariales se encontraban significativamente por debajo de los correspondientes a grupos similares de trabajadores de otras industrias (González Urbaneja, 1976).

\section{LA COMPOSICION DE LA MASA SALARIAL DE RENFE Y SU EVOLUCION}

En este apartado se analiza la evolución de la composición o estructura de la Masa Salarial (MS) de RENFE, distinguiendo cuatro grandes conceptos: el salario-base («haberes y anejos»), que incluye los sueldos y jornales, las pagas extraordinarias, el plus de antigüedad y, hasta 1968, el plus familiar; las horas extraordinarias ( «exceso de jornada»), en las que también se incluyen las «horas especiales», que se diferenciaban de las extraordinarias por percibirse por ellas la misma remuneración que por las horas de jornada normal; "primas", en las que se incluyen diversas primas de carácter fijo, como la de asistencia, y primas ligadas al rendimiento; $y$, por último, un conjunto residual que agrupa una serie de conceptos salariales muy heterogéneos: *gratificaciones» diversas, «indemnizaciones" consistentes casi íntegramente en gastos de viaje y dietas, "premios» y "varios" ${ }^{10}$. Con estas distinciones se pretende, como se ha dicho, una aproximación a la parte fija y variable del salario, aunque la forma originaria de presentación de los datos no ha permitido eliminar totalmente algunos componentes fijos de la parte variable, como las primas de asistencia, a pesar de lo cual se considera que la aproximación lograda es suficientemente significativa. Además del interés intrínseco que tiene en sí mismo, con este análisis se pretende, por una parte, estudiar los cambios producidos a lo largo del periodo en este aspecto clave de la política de personal de la empresa y, por otra parte, completar el análisis realizado en el apartado anterior sobre los determinantes de la evolución de los salarios medios.

10 Para una descripción algo más detallada del contenido de estos conceptos, véase el Apéndice Estadístico. 
Como puede observarse en el cuadro 2, la estructura de la MS de RENFE cambió drásticamente a lo largo del período. Si se toman los dos años extremos se observa que el salario-base ha pasado de representar casi cuatro quintas partes del salario total a representar poco más de la mitad; por la otra parte,

\section{CUADRO 2}

Distribución de la Masa Salarial de RENFE según conceptos salariales, 1943-1975

(En porcentajes)

\begin{tabular}{|c|c|c|c|c|}
\hline$A \bar{n} o s$ & $\begin{array}{l}\text { Haberes } \\
y \text { anejos }\end{array}$ & $\begin{array}{l}\text { Exceso } \\
\text { jornada }\end{array}$ & Primas & Varios \\
\hline $\begin{array}{llllll}1943 & \ldots & \ldots & \ldots & \ldots & \ldots \\
1944 & \ldots & \ldots & \ldots & \ldots & \ldots \\
1945 & \ldots & \ldots & \ldots & \ldots & \ldots \\
1946 & \ldots & \ldots & \ldots & \ldots & \ldots \\
1947 & \ldots & \ldots & \ldots & \ldots & \ldots \\
1948 & \ldots & \ldots & \ldots & \ldots & \ldots \\
1949 & \ldots & \ldots & \ldots & \ldots & \ldots \\
1950 & \ldots & \ldots & \ldots & \ldots & \ldots \\
1951 & \ldots & \ldots & \ldots & \ldots & \ldots \\
1952 & \ldots & \ldots & \ldots & \ldots & \ldots \\
1953 & \ldots & \ldots & \ldots & \ldots & \ldots \\
1954 & \ldots & \ldots & \ldots & \ldots & \ldots \\
1955 & \ldots & \ldots & \ldots & \ldots & \ldots \\
1956 & \ldots & \ldots & \ldots & \ldots & \ldots \\
1957 & \ldots & \ldots & \ldots & \ldots & \ldots \\
1958 & \ldots & \ldots & \ldots & \ldots & \ldots \\
1959 & \ldots & \ldots & \ldots & \ldots & \ldots \\
1960 & \ldots & \ldots & \ldots & \ldots & \ldots \\
1961 & \ldots & \ldots & \ldots & \ldots & \ldots \\
1962 & \ldots & \ldots & \ldots & \ldots & \ldots \\
1963 & \ldots & \ldots & \ldots & \ldots & \ldots \\
1964 & \ldots & \ldots & \ldots & \ldots & \ldots \\
1965 & \ldots & \ldots & \ldots & \ldots & \ldots \\
1966 & \ldots & \ldots & \ldots & \ldots & \ldots \\
1967 & \ldots & \ldots & \ldots & \ldots & \ldots \\
1968 & \ldots & \ldots & \ldots & \ldots & \ldots \\
1969 & \ldots & \ldots & \ldots & \ldots & \ldots \\
1970 & \ldots & \ldots & \ldots & \ldots & \ldots \\
1971 & \ldots & \ldots & \ldots & \ldots & \ldots \\
1972 & \ldots & \ldots & \ldots & \ldots & \ldots \\
1973 & \ldots & \ldots & \ldots & \ldots & \ldots \\
1974 & \ldots & \ldots & \ldots & \ldots & \ldots \\
1975 & \ldots & \ldots & \ldots & \ldots & \ldots\end{array}$ & $\begin{array}{l}79,6 \\
78,8 \\
80,4 \\
78,2 \\
77,9 \\
76,0 \\
71,3 \\
72,8 \\
72,2 \\
68,3 \\
71,7 \\
74,3 \\
74,2 \\
75,1 \\
75,8 \\
72,4 \\
71,1 \\
64,9 \\
64,7 \\
73,6 \\
72,1 \\
68,9 \\
60,4 \\
60,1 \\
61,4 \\
57,2 \\
62,6 \\
56,3 \\
53,2 \\
53,2 \\
52,6 \\
52,5 \\
51,7\end{array}$ & $\begin{array}{l}7,0 \\
7,4 \\
6,2 \\
7,8 \\
7,4 \\
7,1 \\
6,8 \\
6,7 \\
6,6 \\
6,1 \\
6,5 \\
5,9 \\
5,8 \\
6,4 \\
7,9 \\
7,8 \\
7,1 \\
5,5 \\
5,3 \\
4,5 \\
3,8 \\
3,6 \\
4,0 \\
3,6 \\
4,5 \\
4,9 \\
5,8 \\
6,6 \\
6,3 \\
7,1 \\
7,4 \\
7,5 \\
7,0\end{array}$ & $\begin{array}{r}4,3 \\
4,4 \\
3,5 \\
3,5 \\
3,6 \\
4,3 \\
10,8 \\
10,1 \\
10,5 \\
11,1 \\
11,0 \\
9,7 \\
9,9 \\
8,7 \\
5,0 \\
7,3 \\
10,1 \\
19,6 \\
20,1 \\
11,6 \\
13,5 \\
16,8 \\
26,3 \\
27,2 \\
22,6 \\
20,4 \\
17,5 \\
23,2 \\
28,3 \\
27,5 \\
28,3 \\
25,0 \\
22,9\end{array}$ & $\begin{array}{r}9,1 \\
9,3 \\
9,9 \\
10,4 \\
11,1 \\
12,6 \\
11,2 \\
10,4 \\
10,8 \\
14,5 \\
10,8 \\
10,0 \\
10,1 \\
9,8 \\
11,4 \\
12,4 \\
11,7 \\
10,0 \\
9,9 \\
10,4 \\
10,5 \\
10,6 \\
9,3 \\
9,2 \\
11,4 \\
17,6 \\
14,0 \\
13,9 \\
12,2 \\
12,2 \\
11,7 \\
15,0 \\
18,4\end{array}$ \\
\hline
\end{tabular}

FurnTE: Cuadro A.1 del Apéndice Estadístico. 
tanto las «primas» como el conjunto residual de «varios» han ido adquiriendo una importancia creciente. Esta evolución, sin embargo, no ha sido lineal; en algunos años, se observan retrocesos destacables de las tendencias enunciadas y, en determinados subperíodos, éstas tienen una intensidad mucho mayor que en otros.

Si se considera la evolución de la importancia relativa del «salario-base», se pueden distinguir tres grandes fases. La primera corresponde a los tres primeros años, en que esta parte del salario se mantiene en un nivel cercano al 80 por 100 . La segunda fase comienza en 1946, año en que esta parte del salario comienza a perder importancia hasta situarse en un valor medio del 73 por 100 , nivel en torno al cual va oscilando hasta finales de la década de los cincuenta. A partir de esta fecha vuelve a caer $y$, tras algunos retrocesos iniciales, comienza una tendencia decreciente casi ininterrumpida hasta alcanzar el nivel citado de poco más del 50 por 100 en 1975.

¿A qué se deben todos estos cambios? Si prescindimos de la primera fase de estabilidad, el descenso que se observa en los primeros años de la segunda fase (1946-1959) parece deberse a la utilización de otros conceptos salariales como mecanismo de compensación de las pérdidas de poder adquisitivo producidas por los súbitos aumentos de los precios de las subsistencias; como se ha visto, no obstante, esta compensación fue sólo parcial. Unicamente en 1949, año en que se observa un fuerte aumento de las primas, se consiguió mantener el poder adquisitivo del año anterior; como se recordará, se trata del momento en que se introdujeron unas nuevas primas (de movilidad y de regularidad), que se consolidan en los años siguientes como una parte fija de la remuneración. A partir de entonces, la proporción correspondiente a los salarios-base va oscilando con máximos relativos en los años en que se revisa la Reglamentación $(1950,1954,1956-1957)$ y con descensos en los años inmediatamente posteriores, lo cual se explica de nuevo por la utilización de otros conceptos salariales para compensar por la inflación.

En algunos casos, como en 1952, esta compensación comportó un incremento de los salarios reales; el concepto afectado en dicho año fue el de «gratificaciones» (que pasa de representar el 1,4 por 100 de la MS a representar el 5,6 por 100 de la misma), en el que, sin duda, se contabilizó la paga extraordinaria concedida, por una sola vez y con carácter prácticamente general, a finales de dicho año. En cambio, en los años 1958-1959 la compensación fue sólo parcial y se produjeron importantes pérdidas de poder adquisitivo.

En 1960, la proporción correspondiente al salario-base cae en más de 6 puntos. En este caso, la caída responde al fuerte incremento experimentado por la proporción de «primas», que prácticamente se dobla al pasar del 10,1 al 19,6 por 100 . Este incremento parece indicar un cambio fundamental en 
la estrategia de personal y de remuneración de la empresa, a pesar de la interrupción que se observa en 1962 de esta nueva tendencia, al consolidarse parte de las primas, especialmente las de «incentivos de productividad y reducción de efectivos», en la remuneración básica de acuerdo con lo establecido en el nuevo Reglamento de Régimen Interior ( $B O E$ : 30-6-12). En efecto, a partir de 1963 y hasta 1967, la proporción de las primas recupera una clara tendencia creciente, y la de los salarios-base una clara tendencia decreciente.

Esta nueva estrategia de la empresa se inicia en unos momentos en que se procede a una rápida reducción de la plantilla, asociada a los programas de modernización y racionalización de la empresa recomendados por el Banco Mundial en su célebre informe de 1962 (BIRF, 1962: 256-298). Entre 1962 y 1966, el empleo de RENFE cayó en un 14,3 por 100, pasando de 126.000 a 108.000 trabajadores. Parte de la nueva estrategia salarial de la empresa consistió en subrayar la importancia del elemento variable de las ganancias con el fin de facilitar una utilización más flexible del personal y fomentar la «racionalización» y la «eficiencia» de la producción (Sofrerail, 1963: 229; BIRF, 1962: 278-279). Así, en 1963, la Dirección de RENFE enunciaba el principio de que

... debe tenderse a ir sustituyendo la retribución mediante salario por otras formas más modernas de percepción económica, como medio más adecuado de interesar al personal en el esfuerzo común que la modernización de la Red precisa, al hacerle partícipe en los resultados y de mejorar las relaciones sociales en la Empresa (Circular 285, 15-7-63).

Todo esto implicaba la necesidad de ofrecer unos incentivos ligados a las tareas realizadas y la introducción de «primas variables y oscilantes» (ibid.). En 1963 se introdujo una nueva prima «provisional», que explica el aumento del peso del concepto salarial correspondiente observado en dicho año. En 1965 se produjo otro aumento muy importante de esta proporción, de casi 10 puntos, ligado a la introducción de nuevos sistemas de primas relacionadas con la producción para maquinistas, personal de talleres, etc. (Memoria, 1966: 68).

Adviértase, además, que con todo ello se ponían en práctica unos principios que inspiraron numerosos aspectos de la política económica del momento y la admisión de determinados instrumentos como la negociación colectiva de los salarios en algunas empresas. La asunción por parte de RENFE de estos principios constituye un nuevo mecanismo de conexión entre la dinámica salarial del conjunto de la economía y la de esta empresa, que se añade a los analizados en el apartado anterior. 
En estos años, y especialmente a partir de 1967, se observa un incremento importante de los conceptos salariales incluidos en el conjunto residual de «varios». Con la excepción de 1968, este aumento responde principalmente al peso creciente del concepto «indemnizaciones» que, como se ha dicho, está compuesto principalmente por gastos de viaje y dietas. Es probable que este aumento refleje la importancia dada por la Dirección de RENFE a una utilización más flexible del personal, según las recomendaciones del BIRF, que, por ejemplo, indicaba que «RENFE ha de tener facultades para poder transferir el personal cuando le convenga, al implantarse los cambios tecnológicos y procederse a la reorganización» (BIRF, 1962: 279). La fuerte reducción de plantillas de estos años comportó la necesidad de tener que utilizar destacamentos especiales de personal para cubrir las numerosas carencias de personal que, localmente, se produjeron. En 1968, el fuerte aumento de la importancia del grupo «varios» obedece al aumento transitorio del concepto "gratificaciones», que incluye la paga especial concedida a finales de año, tras la descongelación de salarios, tal como se ha señalado en el apartado anterior. El año siguiente, parte de esta gratificación especial se consolidó en la remuneración básica, lo cual explica el aumento temporal de la proporción correspondiente a esta última (Memoria, 1969: 60).

A partir de 1970 se inicia otra fase de descenso continuado de la proporción correspondiente a las remuneraciones básicas. Hasta 1973, este descenso se explica por la continuación del aumento de la proporción de «primas» que, al menos en parte, responde a la introducción de nuevos sistemas de incentivos. Así, en 1970 se introdujo una «prima provisional» de 40 pesetas diarias (Circular 371, 27-1-70; Memoria, 1970: 99, 135) como anticipo de una nueva prima basada en la productividad que se introdujo en 1972 (Circular 387, 28-6-72; Memoria, 1972: 152).

Un último concepto salarial a considerar es el correspondiente a jornada extraordinaria. Como puede observarse, su importancia relativa no ha experimentado grandes variaciones $y$, a finales del período, se mantenía al mismo nivel que a principios del mismo. Pueden distinguirse, no obstante, dos grandes subperíodos: uno de relativa estabilidad, que alcanza hasta 1959, sólo perturbada por unos aumentos notables a partir de 1956 que, probablemente, reflejan la incidencia sobre la remuneración por hora extraordinaria de las revisiones salariales de dicho año; el segundo comienza con los años sesenta y se caracteriza por la pérdida de peso de este concepto salarial, tendencia que cambia de sentido a partir de 1967.

Por no disponer de información sobre el número de horas extraordinarias realizadas, no es posible analizar en qué medida la evolución observada se debe a cambios de esta variable o a cambios del módulo salarial utilizado para 
calcular la remuneración correspondiente. No obstante, puede aventurarse que en el descenso de 1960-1966 este segundo factor podría haber sido el determinante, si se tiene en cuenta el fuerte incremento de las primas en relación a los demás conceptos salariales, ya que lo más probable es que la remuneración por hora extraordinaria dependiera principalmente del salario-base. A partir de 1967, los dos factores mencionados podrían ser responsables del aumento de la importancia de este concepto. Por un lado, la revisión de los salarios-base asociada a la revisión periódica del SMI puede haber hecho aumentar el precio de la hora extra; en 1971, además, se revisó la base de cálculo de las horas extraordinarias (Circular 376, 25-2-71). Por otra parte, es posible que haya aumentado de una manera significativa el número de horas extraordinarias trabajadas debido a dos tipos de razones: primero, a que la empresa sustituyera hombres por horas extraordinarias, en unos años de intensa reducción de plantillas. Entre 1966 y 1975, el empleo de RENFE se redujo en un tercio, pasando de los 108.000 trabajadores mencionados antes a 72.000 (cuadro A.2). El segundo tipo de razones sería que la empresa utilizó con más intensidad este instrumento como expediente para responder a corto plazo a algunas reivindicaciones de los trabajadores o como forma de introducir divisiones entre los mismos. Según medios sindicales, era una práctica habitual en RENFE la concesión discriminada de la oportunidad de obtener unos ingresos adicionales mediante una mayor jornada extraordinaria (Martino de Jugo, 1980: 32).

\section{RESUMEN Y PRINCIPALES CONCLUSIONES}

En este trabajo hemos examinado la evolución de las ganancias medias por trabajador en RENFE, así como la de la composición de la Masa Salarial según diversos conceptos a lo largo de casi todo el período del franquismo, desde 1943 hasta 1975. Con ello, no sólo pretendíamos analizar la evolución de estas variables en una sola empresa, aunque ésta fuera de la importancia de RENFE, sino también ver en qué medida estos datos podían iluminar la evolución de los salarios medios de los trabajadores durante dicho período, aspecto sobre el que sólo se dispone de informaciones muy fragmentarias. Pretendíamos, al mismo tiempo, contrastar algunas hipótesis acerca de los determinantes de la dinámica salarial y, en especial, la importancia que tienen los salarios relativos en la formación de las aspiraciones salariales de los trabajadores y la incidencia del «marco institucional» que guía la fijación de los salarios sobre la dinámica de esta variable $\mathrm{y}$, en particular, como determinante de los diversos «mecanismos de transmisión» que conectan unos salarios con otros. 
Del análisis de la evolución de los salarios medios se deduce la existencia de dos períodos bien diferenciados, con una línea divisoria que se puede situar a comienzos de los años sesenta, cuando se va generalizando en las grandes empresas la práctica de la negociación colectiva posibilitada por la Ley de Convenios de 1958. Durante el primer período, a su vez, se pueden diferenciar dos subperíodos que coinciden con cada una de las dos décadas que lo forman. En la década de los cuarenta se observan importantes fluctuaciones de los salarios reales, tanto de signo negativo como de signo positivo. Las fuertes caídas de los salarios reales son debidas a los súbitos e intensos procesos inflacionistas que experimenta la economía española, originados por importantes crisis de oferta de productos agrarios, en un contexto en que los salarios nominales, fijados burocráticamente por el Ministerio de Trabajo, presentan una relativa rigidez. Estos últimos, por su parte, acaban adaptándose a los nuevos niveles de precios, de forma también muy brusca, y con retrasos que podían variar según empresas o industrias concretas. Esta adaptación se realizó principalmente mediante la revisión de las tarifas salariales básicas determinadas en las Reglamentaciones de Trabajo, aunque otros conceptos salariales ejercieron cierto «papel compensador" y redujeron un tanto las fuertes caídas del poder de compra en los períodos que mediaron entre las sucesivas revisiones de las Reglamentaciones. Por otro lado, la brusquedad de estos procesos de adaptación planteó serios problemas a las empresas no agrarias.

En los años cincuenta, los nuevos sistemas de regulación de las producciones agrarias redujeron las fluctuaciones de los precios de las subsistencias. Sin embargo, el nuevo clima político-social que se iba creando, debido tanto a factores de orden interno como internacional, dieron lugar a fuertes presiones para obtener mejoras del nivel de vida que, dada la responsabilidad asumida por el Estado en la determinación de los salarios, adquirieron un carácter netamente político. Las concesiones obtenidas llevaron, a la vez, a una espiral precios-salarios de naturaleza explosiva, a la crisis del sistema vigente de fijación de salarios y a la sustitución del mismo por un peculiar sistema de negociación colectiva. Los salarios reales siguieron experimentando notables fluctuaciones, aunque de mucha menor amplitud que en la década anterior.

Desde una perspectiva de medio plazo, a lo largo de la primera década, el poder de compra permaneció estable, en un contexto de estancamiento económico y de fuerte represión de toda manifestación abierta y colectiva de descontento. A partir de los primeros años cincuenta, sin embargo, se producen aumentos significativos de los salarios reales en un contexto de crecimiento económico -impulsado, en parte, por dichos aumentos- que permitieron recuperar, hacia mediados de la década, los niveles de vida de los años treinta.

Los datos de RENFE presentan un perfil análogo al que se acaba de des- 
cribir, aunque no se da una coincidencia exacta. En algunos momentos se observan retrasos significativos que, según parece, luego son recuperados con creces. Destaca también el hecho de que, a pesar de que el carácter de empresa pública de RENFE le obligara a aplicar, en mayor medida que en la empresa privada, los niveles salariales dictados por la Administración, la Dirección de la misma dispuso de cierto margen de maniobra a la hora de determinar los salarios. Mediante incrementos de las partes variables del salario, la empresa pudo, por una parte, atemperar en alguna medida las fuertes caídas de los salarios reales producidas por los bruscos e intensos procesos inflacionistas del período y, por otra, recuperar parcialmente el terreno perdido respecto a los salarios de otras empresas.

Tras la promulgación de la Ley de Convenios Colectivos de 1958, la dinámica salarial cambió radicalmente. Aunque se produjeron diversos episodios de espiral precios-salarios, los salarios reales experimentaron unos incrementos notables. La aparición de un "nuevo sindicalismo", asociado a este nuevo instrumento de determinación de los salarios, que competía en búsqueda de legitimidad con el sindicalismo oficial, fue, sin duda, la fuerza principal que impulsó estos incrementos de salarios.

El caso de RENFE muestra una evolución análoga sin que, de nuevo, se dé una coincidencia exacta. En unos primeros momentos, la mayor rigidez de los mecanismos de revisión salarial de RENFE hace que los salarios de la empresa pierdan posiciones, excepto en el momento en que se revisa la Reglamentación. Estos retrasos, no obstante, son resistidos cada vez con mayor fuerza por los trabajadores y, tras diversos conflictos laborales, se instauran cambios institucionales importantes que garantizan una mayor relación entre la evolución de los salarios de la empresa y la de los del conjunto de la industria. En este proceso, además, las nuevas organizaciones de trabajadores en la clandestinidad se convirtieron en el principal mecanismo de transmisión de estos impulsos salariales desde el conjunto de la economía a las empresas que, como RENFE, no pudieron beneficiarse de la negociación colectiva.

El hecho más destacado que muestra el análisis de los cambios experimentados por la estructura de la masa salarial de RENFE, según diversos conceptos salariales, es la mayor importancia que adquieren los componentes variables del salario desde comienzos de los años sesenta. También en este caso, lo acontecido en esta empresa refleja tendencias más generales que se inician en el conjunto de la economía. El incremento de estos componentes variables se debe, por una parte, a la utilización de sistemas de remuneración ligados al rendimiento - cuya expansión pretendía impulsar, a nivel general, la Ley de Convenios Colectivos- y, por otra, a una mayor movilidad geográfica den- 
tro de la empresa para atender las necesidades impuestas por la política seguida de reducción de plantillas.

Desde un punto de vista teórico, el análisis realizado muestra fehacientemente la importancia crucial que tienen los salarios relativos en la formación de las expectativas salariales de los trabajadores. Confirma, asimismo, la importancia del «marco institucional» como determinante de la dinámica de los salarios y de los «mecanismos de transmisión» concretos por los que transcurren los impulsos que imprimen unos salarios a otros que operan en cada momento. Esto no quiere decir que el «marco institucional» de determinación de los salarios y los efectos que pueda tener una configuración particular del mismo sean independientes del entorno económico en el que se encuentran, aunque, ciertamente, no dependen sólo de este entorno, sino también de un conjunto mucho más amplio de factores sociales y políticos.

\section{APENDICE ESTADISTICO}

Como se ha dicho, la información estadística relativa a RENFE analizada en este trabajo fue obtenida de los textos de las Memorias Anuales de la empresa. En este Apéndice se presenta la información de base utilizada y se detallan las principales características de la misma. La presentación se divide en dos apartados dedicados a los dos conjuntos de datos recopilados: los de salarios y los de plantilla.

\section{A.1. Salarios}

En el cuadro A.1 se reproduce la información salarial de base utilizada: siete conceptos salariales cuya suma forma la Masa Salarial Neta, concepto utilizado como dividendo para el cálculo de los salarios medios por trabajador (primera columna del cuadro A.2). Para obtener los costes laborales totales de la empresa debería añadirse a esta cifra el coste de la seguridad social. Los conceptos salariales utilizados comprenden:

\section{a) Haberes y anejos:}

- sueldos y jornales,

- plus de antigüedad,

- pagas extraordinarias,

- plus familiar (hasta 1968). 
b) Exceso de jornada:

- horas extraordinarias,

- horas «especiales» (realizadas fuera de la jornada normal, pero remuneradas igual que las horas ordinarias).

c) Gratificaciones: Tal como se especifica en 1943, esta partida incluye los pagos en concepto de «aguinaldo, actos meritorios, residencia, taquigrafía, buenos servicios y representación sindical». Más tarde fueron incluidas otras gratificaciones «por mando o título» y «por idiomas». Incluye, finalmente, algunas gratificaciones especiales como la de 1968.

d) Primas: Incluye primas fijas, como la de asistencia, y primas variables, ligadas al rendimiento. En 1943 se indica la inclusión de primas por «billetes expedidos; destajos en taller; economía de combustibles, aceite y grasa; recorrido; tiempo ganado en marcha, etc.».

e) Indemnizaciones: Están compuestas, casi íntegramente, por «gastos de viaje y destacamentos». A partir de 1973 se incluye solamente este concepto.

f) Premios: Remuneraciones concedidas por «actos heroicos, actos meritorios, espíritu de servicio, permanencia en la Red, etc.». A partir de 1972 los «premios" se contabilizan como «otros gastos».

g) «Varios»y «otros gastos»: Esta partida experimentó, al parecer, cambios de contenido en diversas ocasiones. En 1943 incluye «descansos no disfrutados», uniformes, remuneración del Servicio de Investigación de los Ferrocarriles (Guardia Civil), medicinas y «ejercicios espirituales». Más adelante parece que el contenido principal de esta partida se reduce a los gastos del Servicio de Investigación y, sobre todo, a «descansos no disfrutados». Entre 1965 y 1972 se distingue una partida de «otras percepciones complementarias», cuyo contenido no se define en las Memorias; parece que, antes y después de este período, la partida citada fue incluida en "varios», concepto al que ha sido sumada en su integridad en los años citados para los que se dispone de esta información separada. A partir de 1973, el concepto de "varios» se ve inflado con la inclusión de gastos por accidentes y enfermedad, que antes se contabilizaban como una partida separada y que no habían sido contabilizados en el total de la Masa Salarial. En estos años, «otros gastos» parece que también incluye los gastos por «reemplazos a categoría superior», partida que parece que, en otras ocasiones, fue contabilizada dentro de «indemnizaciones». 
En el cuadro 2 del texto, los datos anteriores han sido reducidos a cuatro grupos. Los tres primeros coinciden con los conceptos $a$ ), b) y $c$ ) que se acaban de definir. El nuevo grupo de «varios» incluye «gratificaciones», «indemnizaciones», "premios» y el concepto residual de «varios».

\section{A.2. Plantilla}

Los datos de plantilla que se reproducen en el cuadro A.2 se han tomado también de las diversas ediciones de la Memoria Anual. Todos los datos se refieren al 31 de diciembre de cada año (o al 1 de enero del año siguiente).

Las cifras de plantilla incluyen tanto los efectivos fijos como los eventuales; estos últimos alcanzaron un máximo de 27.000 , en 1943, y estaban empleados principalmente en vías y obras. Hasta mediados de los cincuenta, el número de eventuales fue elevado; durante los sesenta descendieron hasta 2.000-4.000 y, desde 1968, cayeron a cifras insignificantes. A partir de 1972 no se presentan datos separados para este colectivo que, en dicha fecha, sólo estaba compuesto por 133 trabajadores.

Estos datos también incluyen a los «militares en prácticas» y a los «contratados». Algunos años las Memorias anuales presentan datos desagregados sobre los trabajadores «fijos» de la «plantilla ferroviaria» y los trabajadores fijos de otros establecimientos. Por ejemplo, en 1952, el grupo de fijos de otros establecimientos comprende al «grupo de investigación de la Guardia Civil» y a los "Cuadros Subalternos de la Guardería Jurada»; los aprendices en escuelas y los "aspirantes a Factor en espera de vacante», y un número muy reducido de trabajadores en «organismos oficiales vinculados al Ferrocarril». En 1954 se detalla que los trabajadores forestales y el personal del economato también se incluyen dentro de la plantilla, aunque en años subsiguientes los trabajadores forestales dejaron de ser computados en estos datos.

Entre 1954 y 1956 no aparecen datos sobre la plantilla efectiva, sino que sólo se proporciona información sobre los trabajadores «fijos» y los «eventuales suplentes de vacantes». Los datos correspondientes a estos años y los correspondientes a 1957 han sido tomados de la Memoria de 1958 (p. 93). La Memoria de 1957 ofrece datos para el 1 de enero y para el 31 de diciembre de 1957, pero estos datos difieren en unas 2.000-3.000 personas de los ofrecidos para el 31 de diciembre de 1956 y el 31 de diciembre de 1957, respectivamente, por la Memoria de 1958. Los datos utilizados son estos últimos.

La serie de plantilla presentada en el cuadro A.2 no coincide, en todos los años, con la que se reproduce en RENFE (1983: 158), para el período 1948-1983. Creemos que las principales discrepancias se explican por el dis- 
tinto tratamiento que en una y otra serie se hace de los colectivos que acabamos de mencionar. En algún caso, además, la segunda serie ha reproducido algunos datos retrospectivos de alguna edición de la Memoria en que no se especifica bien qué colectivos han sido incluidos y cuáles no.

\section{CUADRO A.1}

Masa Salarial Neta de RENFE según conceptos salariales, 1943-1975

(En millones de pesetas)

\begin{tabular}{|c|c|c|c|c|c|c|c|}
\hline$A \tilde{n} o s$ & $\begin{array}{l}\text { Haberes } \\
\text { y anejos }\end{array}$ & $\begin{array}{c}\text { Exceso } \\
\text { jornada }\end{array}$ & $\begin{array}{l}\text { Gratifi- } \\
\text { caciones }\end{array}$ & Primas & $\begin{array}{l}\text { Indemni- } \\
\text { zaciones }\end{array}$ & Premios & Varios \\
\hline 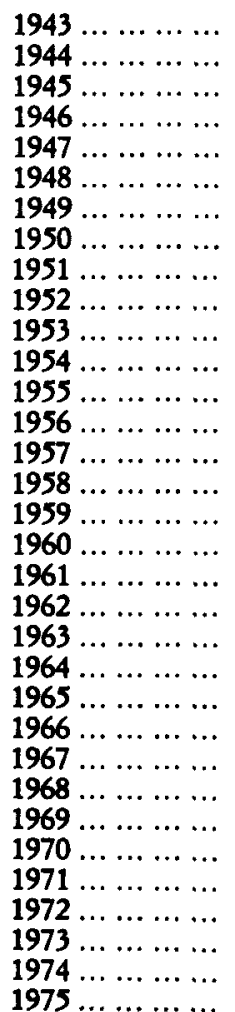 & $\begin{array}{r}554,4 \\
584,7 \\
820,0 \\
896,3 \\
905,1 \\
965,4 \\
1.028,0 \\
1.399,2 \\
1.530,1 \\
1.589,6 \\
1.619,3 \\
1.969,2 \\
2.052,9 \\
2,375,7 \\
2.944,5 \\
2.972,0 \\
2.982,2 \\
3.014,9 \\
2.968,7 \\
4.333,1 \\
5.114,9 \\
4.973,1 \\
4.773,6 \\
4.953,8 \\
5.725,0 \\
5.505,6 \\
6.114,0 \\
5.612,0 \\
6.529,0 \\
7.233,0 \\
8.195,0 \\
9.678,0 \\
11.4920\end{array}$ & $\begin{array}{r}48,6 \\
54,9 \\
63,4 \\
89,5 \\
86,0 \\
89,9 \\
97,9 \\
128,2 \\
138,8 \\
141,5 \\
146,7 \\
157,2 \\
161,2 \\
202,4 \\
307,1 \\
319,8 \\
298,4 \\
255,8 \\
242,6 \\
262,1 \\
272,7 \\
261.8 \\
314,7 \\
295,0 \\
418,8 \\
468,1 \\
568,0 \\
655,0 \\
769,0 \\
959,0 \\
1.152,0 \\
1.376,0 \\
1546,0\end{array}$ & $\begin{array}{r}4,8 \\
5,7 \\
14,3 \\
13,2 \\
14,2 \\
19,9 \\
23,5 \\
30,4 \\
29,0 \\
129,4 \\
29,6 \\
32,9 \\
35,1 \\
37,6 \\
37,8 \\
59,5 \\
61,1 \\
68,7 \\
70,2 \\
93,9 \\
107,2 \\
84,9 \\
102,2 \\
97,8 \\
118,8 \\
669,6 \\
212,0 \\
204,0 \\
245,0 \\
281,0 \\
235,0 \\
303,0 \\
3070\end{array}$ & $\begin{array}{r}30,1 \\
32,9 \\
35,2 \\
40,5 \\
42,4 \\
54,5 \\
155,4 \\
194,2 \\
221,6 \\
257,9 \\
249,5 \\
256,8 \\
273,5 \\
273,9 \\
193,9 \\
300,3 \\
423,3 \\
909,6 \\
924,8 \\
681,0 \\
961,0 \\
1.214,8 \\
2.077,9 \\
2.239,7 \\
2.106,6 \\
1.963,6 \\
1.714,0 \\
2.314,0 \\
3.469,0 \\
3.741,0 \\
4.404,0 \\
4.596,0 \\
5.078,0\end{array}$ & $\begin{array}{r}48,4 \\
55,1 \\
74,3 \\
81,4 \\
83,8 \\
96,7 \\
105,2 \\
138,8 \\
158,7 \\
163,0 \\
165,9 \\
187,3 \\
196,7 \\
214,0 \\
301,9 \\
310,1 \\
302,7 \\
273,5 \\
264,9 \\
379,6 \\
465,5 \\
464,4 \\
527,7 \\
562,6 \\
776,8 \\
814,5 \\
994,0 \\
1.023,0 \\
1.082,0 \\
1.171,0 \\
970,0 \\
1.074,0 \\
1492,0\end{array}$ & $\begin{array}{r}0,0 \\
0,1 \\
0,1 \\
0,0 \\
0,1 \\
0,1 \\
0,1 \\
0,3 \\
1,2 \\
2,2 \\
1,6 \\
1,2 \\
1,0 \\
1,0 \\
11,6 \\
12,0 \\
12,6 \\
14,8 \\
14,6 \\
11,7 \\
13,9 \\
50,5 \\
14,5 \\
11,6 \\
17,3 \\
42,0 \\
40,0 \\
23,0 \\
17,0 \\
21,0 \\
0,0 \\
0,0 \\
0.0\end{array}$ & $\begin{array}{r}9,8 \\
8,3 \\
12,6 \\
24,7 \\
31,0 \\
43,9 \\
32,6 \\
31,2 \\
39,6 \\
43,1 \\
46,0 \\
44,4 \\
46,8 \\
57,9 \\
90,0 \\
129,0 \\
112,7 \\
108,9 \\
105,5 \\
126,0 \\
158,2 \\
164,2 \\
90,9 \\
86,5 \\
153,3 \\
167,1 \\
126,0 \\
134,0 \\
154,0 \\
180,0 \\
616,0 \\
1.390,0 \\
2296,0\end{array}$ \\
\hline
\end{tabular}

FUENTE: RENFE, Memoria Anual (diversas ediciones). 


\section{CUADRO A.2}

Masa Salarial, Plantilla Total, Indice del Coste de la Vida y Salario Medio, nominal y real, por trabajador en RENFE, 1943-1975

\begin{tabular}{|c|c|c|c|c|c|}
\hline \multirow[b]{2}{*}{ Años } & \multirow[b]{2}{*}{$\begin{array}{c}\text { Masa } \\
\text { salarial }\end{array}$} & \multirow[b]{2}{*}{$\begin{array}{c}\text { Plantilla } \\
\text { total }\end{array}$} & \multirow[b]{2}{*}{$I P C$} & SALARIO & MEDIO \\
\hline & & & & Nominal & - Real \\
\hline $\begin{array}{llllll}1943 & \ldots & \ldots & \ldots & \ldots & \ldots \\
1944 & \ldots & \ldots & \ldots & \ldots & \ldots \\
1945 & \ldots & \ldots & \ldots & \ldots & \ldots \\
1946 & \ldots & \ldots & \ldots & \ldots & \ldots \\
1947 & \ldots & \ldots & \ldots & \ldots & \ldots \\
1948 & \ldots & \ldots & \ldots & \ldots & \ldots \\
1949 & \ldots & \ldots & \ldots & \ldots & \ldots \\
1950 & \ldots & \ldots & \ldots & \ldots & \ldots \\
1951 & \ldots & \ldots & \ldots & \ldots & \ldots \\
1952 & \ldots & \ldots & \ldots & \ldots & \ldots \\
1953 & \ldots & \ldots & \ldots & \ldots & \ldots \\
1954 & \ldots & \ldots & \ldots & \ldots & \ldots \\
1955 & \ldots & \ldots & \ldots & \ldots & \ldots \\
1956 & \ldots & \ldots & \ldots & \ldots & \ldots \\
1957 & \ldots & \ldots & \ldots & \ldots & \ldots \\
1958 & \ldots & \ldots & \ldots & \ldots & \ldots \\
1959 & \ldots & \ldots & \ldots & \ldots & \ldots \\
1960 & \ldots & \ldots & \ldots & \ldots & \ldots \\
1961 & \ldots & \ldots & \ldots & \ldots & \ldots \\
1962 & \ldots & \ldots & \ldots & \ldots & \ldots \\
1963 & \ldots & \ldots & \ldots & \ldots & \ldots \\
1964 & \ldots & \ldots & \ldots & \ldots & \ldots \\
1965 & \ldots & \ldots & \ldots & \ldots & \ldots \\
1966 & \ldots & \ldots & \ldots & \ldots & \ldots \\
1967 & \ldots & \ldots & \ldots & \ldots & \ldots \\
1968 & \ldots & \ldots & \ldots & \ldots & \ldots \\
1969 & \ldots & \ldots & \ldots & \ldots & \ldots \\
1970 & \ldots & \ldots & \ldots & \ldots & \ldots \\
1971 & \ldots & \ldots & \ldots & \ldots & \ldots \\
1972 & \ldots & \ldots & \ldots & \ldots & \ldots \\
1973 & \ldots & \ldots & \ldots & \ldots & \ldots \\
1974 & \ldots & \ldots & \ldots & \ldots & \ldots \\
1975 & \ldots & \ldots & \ldots & \ldots & \ldots\end{array}$ & $\begin{array}{r}696,1 \\
741,7 \\
1.019,9 \\
1.145,6 \\
1.162,6 \\
1.270,4 \\
1.442,7 \\
1.922,3 \\
2.119,0 \\
2.326,7 \\
2.258,6 \\
2.649,0 \\
2.767,2 \\
3.162,5 \\
3.886,8 \\
4.102,7 \\
4.193,0 \\
4.646,2 \\
4.591,3 \\
5.887,4 \\
7.093,4 \\
7.213,7 \\
7.901,5 \\
8.247,0 \\
9.316,6 \\
9.630,5 \\
9.768,0 \\
9.965,0 \\
12.265,0 \\
13.586,0 \\
15.572,0 \\
18.417,0 \\
22.211,0\end{array}$ & $\begin{array}{r}123.131 \\
121.461 \\
116.137 \\
118.095 \\
120.176 \\
124.781 \\
132.714 \\
132.912 \\
137.196 \\
139.068 \\
139.457 \\
137.622 \\
135.321 \\
133.400 \\
132.378 \\
130.345 \\
129.246 \\
129.328 \\
127.443 \\
126.467 \\
119.815 \\
114.072 \\
111.240 \\
108.510 \\
104.518 \\
98.260 \\
88.216 \\
82.624 \\
78.972 \\
76.960 \\
73.377 \\
72.733 \\
72.223\end{array}$ & $\begin{array}{l}100,0 \\
104,3 \\
111,7 \\
146,6 \\
172,4 \\
184,1 \\
194,0 \\
215,1 \\
235,3 \\
230,7 \\
234,4 \\
237,2 \\
246,9 \\
261,3 \\
289,5 \\
328,3 \\
352,2 \\
356,4 \\
362,4 \\
382,9 \\
416,4 \\
445,4 \\
504,3 \\
535,6 \\
570,3 \\
598,1 \\
610,9 \\
646,0 \\
699,2 \\
757,2 \\
843,9 \\
976,0 \\
1.141,7\end{array}$ & $\begin{array}{r}5.653,3 \\
6.106,5 \\
8.781,9 \\
9.700,7 \\
9.674,1 \\
10.181,0 \\
10.870,7 \\
14.463,0 \\
15.445,1 \\
16.730,7 \\
16.195,7 \\
19.248,4 \\
20.449 .2 \\
23.706,9 \\
29.361,4 \\
31.475,7 \\
32.442,0 \\
35.925,7 \\
36.026,3 \\
46.552,9 \\
59.202,9 \\
63.238,1 \\
71.031,1 \\
76.002,2 \\
89.138,7 \\
98.010,4 \\
110.728,2 \\
120.606,6 \\
155.308,2 \\
176.533,3 \\
212.219,1 \\
253.213,8 \\
307.533,6\end{array}$ & $\begin{array}{r}5.653,3 \\
5.854,7 \\
7.862,0 \\
6.617,1 \\
5.611,5 \\
5.530,2 \\
5.603,5 \\
6.723,8 \\
6.564,0 \\
7.252,1 \\
6.909,4 \\
8.114,8 \\
8.282,4 \\
9.072,7 \\
10.142,1 \\
9.587,5 \\
9.211,2 \\
10.080,2 \\
9.941,0 \\
12.158,0 \\
14.217,8 \\
14.198,1 \\
14.085,1 \\
14.190,1 \\
15.630,1 \\
16.387,0 \\
18.125,4 \\
18.669,8 \\
22.212,3 \\
23.314,0 \\
25.147,4 \\
25.944,0 \\
26.936,5\end{array}$ \\
\hline
\end{tabular}

Furntes: - Datos relativos a RENFE: RENFE, Memoria Anual (diversas ediciones). Masa salarial: en millones de pesetas. Salario medio: en pesetas.

- IPC: Indice de Precios de Consumo calculado a partir de las aseries enlazadas* publicadas en INE (1979: 159-160). 1943-1961: datos correspondientes al *conjunto nacional urbanow; 1961-1975: datos correspondientes al «conjunto nacional total». 


\section{BIBLIOGRAFIA}

Alcaide, Julio (1965): «Aspectos de la evolución de los salarios en España», Información Comercial Española, núm. 381, mayo.

BIRF (1962): Informe del Banco Internacional de Reconstrucción y Fomento. El desarrollo económico de España, Oficina de Coordinación y Programación Económica, Madrid.

BuLNES, Ramón (1967): «Realidad y perspectivas de la lucha sindical en la RENFE», Cuadernos de Ruedo Ibérico, núm. 11.

CAÑıS, Luis (1976): «Salarios: el franquismo perjudica a los trabajadores», Doblón, núm. 88, $19-25$ junio.

Carballo, Roberto (1976): «Salarios», en Varios Autores: Anuario de las Relaciones Laborales en España, Ediciones de la Torre, Madrid.

Clavera, Joan, et al. (1978): Capitalismo español: de la autarquía a la estabilización (1939-59), 2: ed., EDICUSA, Madrid.

Dunlop, John T. (1957): «The task of contemporary wage theory», en J. T. DunLop (ed.): The Theory of Wage Determination, Macmillan, Londres.

Ferner, Anthony (1987): «Industrial Relations an the Mesopolitics of the Public Enterprise: The Transmission of State Objectives in the Spanish National Railways», British Journal of Industrial Relations, vol. XXV, marzo.

FinA, Lluís (1978): «Política salarial i lluita de classes sota el franquisme», Materiales, núm. 7.

- (1979): Convenios y Salarios en el Sector Metalúrgico Español, 1960-1975, tesis doctoral, Universitat Autònoma de Barcelona.

Fontana, Josep, y Nadal, Jordi (1976): «Spain, 1914-1970m, en Carlo M. Cipolla (ed.): The Fontana Economic History of Europe. Contemporary Economies. Part two, Collins/ Fontana Books, Glasgow.

Gonzílez Urbaneja, Fernando (1976): «La RENFE se viste de azul», Doblón, 7 febrero.

ICE (1962): «Un análisis estadístico de los salarios», Información Comercial Española, núm. 352, diciembre.

INE (1966): «Remuneraciones medias efectivas por hora de trabajo para los años 1959, 1960, 1961 y 1962», Revista de Trabajo, núm. 15.

- (1979): Indice de Precios de Consumo. Monografía Técnica, Madrid.

- (1982): Metodología de la Encuesta de Salarios. Monografia Técnica, Madrid.

LORENTE, José Ramón (1982): «Notas críticas sobre las estadísticas salariales españolas», en Ministerio de Economía y Comercio, Secretaria General Técnica: El mercado de trabajo en España, Gráficas Reunidas, S. A., Madrid.

Maluquer de Motes, Jordi (1987): «Salarios y Renta Nacional (1913-1959)», en Alvaro Espina, Lluís Fiñ y Felipe Ś́ez (comps.): Estudios de Economía del Trabajo en España. II. Salarios y Política de Rentas, Ministerio de Trabajo y Seguridad Social, Centro de Publicaciones, pp. 959.978.

Martino de Jugo, José Luis (1980): Los ferroviarios en Comisiones Obreras. Datos para la bistoria del movimiento obrero, 1964-80, Secretaría de Información y Publicaciones del Sindicato Ferroviario de CC. OO., Madrid.

Molinero, Carme, e Ysis, Pere (1985): «Patria, Justicia y Pan». Nivell de vida $i$ condicions de treball a Catalunya, 1939-1959, Edicions de La Magrana, Barcelona.

Perpiñर Rodrfguez, Antonio (1962): La estructura de salarios en España. Estudio sobre el salario diferencial, Consejo Superior de Investigaciones Científicas, Instituto «Balmes» de Sociología, Madrid.

Prore, Michael (1973): «Fragments of a "Sociological" Theory of Wages», American Eco. nomic Review, mayo.

RENFE (1983): Balance Social 82/83, Madrid. 
Serrano, Angel, y Malo de Molina, José Luis (1979): Salarios y Mercado de Trabajo en España, H. Blume Ediciones, Madrid.

Sofrerall (1963): Modernization Plan of the RENFE. Report. París.

Torres, Manuel de (1956): Juicio de la actual politica económica, Editorial Aguilar, Madrid.

Velarde Fuertes, Juan (1973): «La Revista de Trabajo, once años después», Revista de Trabajo, núms. 41-42, vol. 1. 